BNL-HCS-51684

[ENDF-331]

UC-34C

[Physics-Huclear-TIC-4500]

\title{
AN ANNOTATED BIBLIOGRAPHY COVERING GENERATION AND USE OF EVALUATED CROSS SECTION UNCERTAINTY FILES*
}

\author{
A.W. Peelle \\ Oak Ridge National Laboratory \\ Oak Ridge, Tennessee 37830 \\ T.W. Burrows \\ National Nuclear Data Center \\ Brookhaven National Laboratory \\ Upton, Long Island, New York 11973
}

BHI - HCS -51684

DE83 017884

\section{March 1983}

DISCLAIMER

This report was prepared as an account of work sponsored by an agency of the United States Government. Neither the United States Government nor any agency thereof, nor any of their employees, makes any warranty, express or implied, or assumes any legal liability or responsibility for the accuracy, completeness, or usefulness of any information, apparatus, product, or process disclosed, or represents that its use would not infringe privately owned rights. Reference herein to any specific commercial product, process, or service by trade name, tradernark, manufacturer, or otherwise does not necessarily constitute or imply its endorsement, recommendation, or favoring by the United States Government or any agency thereof. The views and opinions of authors expressed herein do not necessarily state or reflect those of the United States Government of any agency thereof.

* Research sponsored by the Division of Reactor Research and Technology, Unifed States Department of Energy, under contract W-7405-eng-26 with the Union Carbide Corporation, and also in part under contract NO. DE-AC02-76CH00016 with the United States Department of Energy. 
TABIE OF CONTENTS

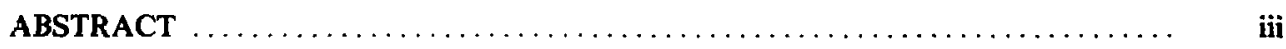

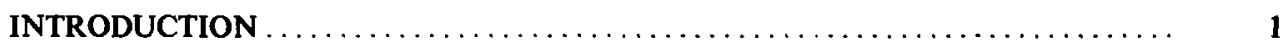

1. THE COVARIANCE MATRIX FOR RESULTS OF AN EXPERIMENT ....... 3

2. COVARIANCE DATA FOR THE OUTPUT OF NUCLEAR MODEL CODES .... 7

3. EVALUATION AND REPRESENTATION OF COVARIANCE DATA FOR EVALUATED NUCLEAR CROSS-SECTIONS $\ldots \ldots \ldots \ldots \ldots \ldots \ldots \ldots \ldots$

3.1 Methods, Formats, and Procedures $\ldots \ldots \ldots \ldots \ldots \ldots \ldots \ldots \ldots \ldots \ldots \ldots$

3.2 Documented Examples of Nuclear Data Covariance Evaluations ........... 12

4. COMPILATIONS OF CROSS SECTION COVARIANCE DATA $\ldots \ldots \ldots \ldots \ldots \ldots$

5. THE UNCERTAINTY IN NUCLEAR SYSTEM ANALYSIS RESULTS

THAT IS INDUCED BY NUCLEAR DATA UNCERTAINTY . . . . . . . . . 18

6. COMBINATION OF DIFFERENTIAL AND INTEGRAL DATA

UTILIZING COMPLETE COVARIANCE DATA $\ldots \ldots \ldots \ldots \ldots \ldots \ldots \ldots, \mathbf{2 1}$

7. DESCRIPTIONS OF COMPUTER CODES THAT PRODUCE OR MANIPULATE NUCLEAR DATA COVARIANCE FILES $\ldots \ldots \ldots \ldots \ldots \ldots \ldots \ldots \ldots \ldots \ldots$

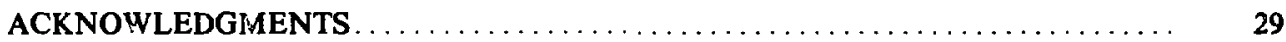




\title{
AN ANNOTATED BIBLIOGRAPHY COVERING GENERATION AND USE OF EVALUATED CROSS SECTION UNCERTAINTY FILES
}

\author{
R. W. Peelle \\ Oak Ridge National Laboratory \\ Oak Ridge, Tennessee 37830 \\ and \\ T. W. Burrows \\ Brookhaven National Laboratory \\ Upton, New York 11973
}

\begin{abstract}
Literature references related to definition, generation, and use of evaluated cross section uncertainty (variance-covariance) files are listed with comments intended primarily to guide the reader toward materials of immediate interest. Papers are also cited that cover covariance information for individual experiments and that relate to production and use of multigroup covariance matrices. Titles are divided among several major categories.
\end{abstract}




\section{INTRODUCTION}

Evaluated files of uncertainty (variance-covariance) information for nuclear cross sections and related quantities have gradually become available over recent years, in response to demands for quantitative measures of the expected accuracy of nuclear analyses. Since the methods for nuclear system analyses have been so thoroughly studied, the uncertainties in and correlations among the input data are important if not dominant contributors to output uncertainty.

As the use of uncertainty and correlation data has expanded, and as evaluators have tried to learn valid techniques that combine data to produce evaluated uncertainties and correlations as well as evaluated cross sections, there has developed a thirst for facilitated access to the pertinent literature for each phase of the required effort from file generation to the various applications of processed data. This annotated bibliography, designed to provide that facilitated access, was developed because of a request to the Covariance Subcommittee of the U.S. Cross Section Evaluation Working Group. Since evaluated cross section files are based on combinations of theory and experiments, papers are cited that consider provision of covariance data for each type of source information. Most applications require group covariance matrices to be generated from the evaluated covariance files, so papers covering this processing are also included. Included are titles of papers that expressly discuss methods and those that are examples of applications of such methods.

The codified uncertainty data referred to here are sometimes called covariance files and sometimes uncertainty files; in either case they symmarize evaluated information concerning the uncertainties in the related evaluated cross section quantities and the correlations among those quantities for various materials and reaction types and at different incoming (and outgoing) energies. In every case these variance-covariance data are properties of the knowledge available to the cross section evaluator about physical quantities that have unknown true values.

The entries in this bibliography refer, with few exceptions, to the widely available journal and report literature. The emphasis is on the ENDF/B uncertainty files and covariance data derived from them, but most of the material is more general. The intention is to update this bibliograpy on a few-year 
cycle, so a bibliographic data base has been established at the NNDC. The authors hope that readers will submit for future inclusion any important papers and reports that have not yet been included.

The body of this report is divided among a series of categories, and a given title is listed alphabetically by first author under the first category to which it makes a strong contribution. When the same paper makes a quite important contribution in a second category, it is sometimes listed again. The categories used are shown in the Table of Contents. No claim is made as to the completeness of this bibliography, particularly on topics for which there are many papers. Comments on the contents of the various papers are those of the bibliography's first author, and may not reflect any broad concensus. 


\section{THE COVARIANCE MATRIX FOR RESULTS OF AN EXPERIMENT}

This section includes papers that deal with the determination of covariance (and variance) components for the results of a single experiment or set of experiments. The principles are not different from those needed for the joint evaluation of results from several experiments as in Section 3, but in the present case there is great variety in the relationship between the observations and the quantities reported as experimental results.

J. K. Dickens et al., "Fission-Product Energy Release for Times Following Thermal-Neutron Fission of ${ }^{235}$ U Between 2 and 14000 s, " Nucl. Sci. Eng. 74, 106-129 (1980).

This is an example of a paper in which a complete variance-covariance matrix of the thirty-odd principal results is presented, along with an explanation of its components. Similar results are given for other samples in Nucl. Sci. Eng. 78, 126 (1981).

N. M. Larson and F. G. Perey, User's Guide for SAMMY: A Computer Model for Multilevel RMatrix Fits to Neutron Data Using Bayes' Equations, ORNL/TM-7485 (ENDF-297), Oak Ridge National Laboratory, November 1980.

SAMMY solves the least-squares equations in the adjustment form, here called the "Bayes' equations", for R-matrix parameters in the Reich-Moore approximation. Experimental data is fed in by segments, and each such experiment is assumed to be uncorrelated to the others. Parameters and the parameter covariance matrix properly preserve and condense the information from resonance data previously fed into the system. Explicit provision is made in SAMMY for accepting the full covariance matrix of a set of input cross section data or for generating within the program covariance matrices of particularly simple form. Therefore, the output parameter covariance matrices from this program can be more valid than those from fitting programs that assume diagonal input data variance-covariance matrices. 
N. M. Larson, User's Guide for BAYES: A General-Purpose Computer Code for Fitting a Functional Form to Experimental Data, ORNL/TM-8185, Oak Ridge National Laboratory, 1982.

This report describes program packages for general least square data combination and fitting, permitting and facilitating the use of nondiagonal covariance matrices of input data. The BAYES package uses the "Bayes' Equations" of least-square parameter adjustment, while the LEAST package solves the conventional nonlinear least squares problem. When correct input data covariances are provided and the theory used is consistent with the data, the output parameter covariance matrix is a valid propagation of uncertainty.

Examples are given for using the program in data reduction to handle correctly the covariance terms introduced by data normalization and by background subtraction.

W. Mannhart, A Small Guide to Generating Covariances of Experimental Data, Bericht FMRB-84, ISSN 0341-6666, Physikalisch-Technische Bundesanstalt, Forschungs und MeAreaktor Braunschweig, June 1981.

This report was written expressly to provide a guide for experimenters who wish to derive covariance data for their experimental results. A number of examples familiar to nuclear experimenters are employed to illustrate the solution to typical problems. The text is exceptionally clear on the inclusion of "non-statistical" or "systematic" uncertainties with "statistical" ones.

The present author agrees with Mannhart that experimental papers should list uncertainty components with correlations, but disagrees with his position that the covariance matrix need not be given. Typically, ambiguities are present that are resolved only by display of the matrix.

R. W. Peelle, "Uncertainties and Correlations in Evaluated Data Sets Induced by Use of Standard Cross Sections," pp. 173-176 in Proc. Conf. on Nuclear Cross Sections and Technology, March 3-7, 1975, R. A. Schrack and C. D. Bowman, Editors, NBS-SP-425, Vol. 1, National Bureau of Standards, 1975.

Though this paper is phrased in terms of an evaluation combining several experimental results that depend on standards in different ways, its value lies mainly in its explicit differentiation among the forms of covariance matrix contributions that arise: (1) from use of a standard cross section defined at 
a particular energy, (2) use of an energy-dependent "absolute" standard, and (3) an energy-dependent relative or "shape" standard.

R. W. Peelle, "Requirements on Experiment Reporting to Meet Evaluation Needs," pp. 421-429 in Proc. of NEANDC/NEACRP Specialists ideeting on Fast Neutron Fission Cross Sections of U-233, U-235, U-238, and Pu-239, June 28-30, 1976, W. P. Poenitz and A. B. Smith, Editors, ANL-76-90 [ERDANDC-5/L, NEANDC'US)-199/L], Argonne National Laboratory.

This paper presents a "model" of an evaluation to motivate experimenters to include in their writeups enough information about the uncertainties in their results. The equivalent of the variancecovariance matrix of reported data is shown to be required. (See additional notes in Section 3.1).

F. G. Perey, "Covariance Matrices of Experimental Data," p. 104 in Proc. of Inter. Conf. on Neutron Physics and Nuclear Data for Reactors and other Applied Purposes, Harwell, United Kingdom, OECD Nuclear Energy Agency, Paris, 1978.

This paper offers the determination of neutron resonance energies by the time-of-flight method as a compelling and clear example of the use of covariance data in data reduction. For some previously analyzed data, Perey shows that consideration of the correlations among various observations resolves apparent ambiguities and leads to a reduction in the previously estimated final resonance energy uncertainties.

F. G. Perey, Application of Group Theory to Data Reduction, ORNL-5908, Oak Ridge National Laboratory, 1982.

This report lays a firm groundwork for a general method of data reduction that intrinsically includes treatment of non-statistical experimental uncertainties. Group theory provides the framework. Many of the accustomed laws of probability are shown to follow from this approach without use of difficult concepts such as "randomness." At its present stage of development the method described provides a conceptual framework for thinking clearly about nonstatistical or "systematic" errors, but only modest practical help to a typical experimenter who attempts to codify the density functions of experimental results. 
D. L. Smith, Covariance Matrices and Applications to the Field of Nuclear Data, ANL/NDM-62, Argonne National Laboratory, November 1981.

The author sets out to provide "a student's introduction to covariance error analyses and leastsquares evaluation of data...," and succeeds well. The student is assumed to be a nuclear experimenter. The concepts are presented from a geometric approach that many will find helpful. Good examples are given of how an experimenter can assemble covariance information in specific cases. A more recent companion report by the same author, Non-Evaluation Applications For Covariance Matrices, ANL/NDM-67, Argonne National Laboratory, May 1982, gives additional examples. The example starting on p. 81 of NDM-67 is particularly pertinent in its treatment of dominant error components for cross section ratio measurements.

The present author disagrees somewhat with Smith's thought thaî rather complete uncertainty data may be required only for experiments on a few standards, though that work does have priority. A logical, complete recording of uncertainties by the experimenter seems necessary for any serious measurement of numerical quantities of practical or scientific importance. If experimenters do not take the trouble to develop covariance information, evaluators or other users must ignore the data or more likely make incorrect assumptions about its information content.

G. Winkler, Donald L. Smith, and James W. Meadows, "Measurement of Cross Sections for the ${ }^{63} \mathrm{Cu}(\mathrm{n}, \alpha){ }^{60} \mathrm{Co}$ Reaction from Threshold to $10 \mathrm{MeV}$," Nicl. Sci. Eng. 76, 30-42 (1980).

This paper is a good example of what appears to be complete reporting of covariance information by an experimental group. The uncertainty components are listed and the resulting "relative covariance matrix" (correlation matrix) is tabulated to avoid ambiguities. 


\section{COVARIANCE DATA FOR THE OUTPUT OF NUCLEAR MODEL CODES}

In a sense a nuclear model code is a method for combining often diverse nuclear data to obtain consistent interpolated values. However, as broader "physics" input is included, the appropriate treatment of covariance information has seemed obscure. One may expect considerable future advances in this area.

J. B. Dragt et al., "Methods of Adjustment and Error Evaluation of Neutron Capture Cross Sections," Nucl. Sci. Eng. 62, 119 (1977); J. B. Dragt and H. Gruppelaar, Error Analysis of Neutron Capture Group Cross Sections for Fast Reactors Applied to Fission Products, RCN-192 (URFNR-1132) 1973; H. Gruppelaar, "Uncertainty ìstimates of Statistical Theory Calculations of Neutron Capture Cross Sections of Fission Product Nuclei," p. 61 in Proc. IAEA Consultants Meeting on the Use of Nuclear Theory in Neutron Nuclear Data Evaluation, IAEA-190, Vol. II, 1975.

In Section $V$ of the first paper the unadjusted shielded group capture cross sections are computed from resonance or statistical model theory, and the correlations among the resulting group cross sections are obtained. Correlations among parameters for the same resonance are taken as null. In the region where the statistical model is employed, uncertainties from both the model parameters and the statistical nature of the model are considered. The model parameter uncertainties are obtained as part of the evaluation of those parameters.

S. Pearlstein, "Analysis of Neutron Emission Spectra from 14-MeV Neutron Reactions," Nucl. Sci. Eng. 68, 55-60 (1978).

In this paper a global least squares fit to observed neutron emission spectra following $14-\mathrm{MeV}$ neutron reactions is performed using equilibrium and pre-equilibrium reaction models. The uncertainties and correlations in the modei parameters are propagated to the interpolated intensity and high-energy fraction para neters for the same nuclides for which experimental data were entered. The propagated uncertainties are statsed to be too small, but do represent uncertainty data for the output of a nuciear model code. Doubt is expressed in the paper that the model employed represents more than a semiphysical description of nuciear properties or reaction mechanisms, and indeed the residuals are generally much larger than the input uncertainties. 


$$
-8-
$$

B. Strohmaier, S. Tagesen, and H. Vonach, "Evaluation of the Cross-Sections for the Reactions ${ }^{19} \mathrm{~F}(\mathrm{n}, 2 \mathrm{n}){ }^{18} \mathrm{~F},{ }^{31} \mathrm{P}(\mathrm{n}, \mathrm{p})^{31} \mathrm{Si},{ }^{93} \mathrm{Nb}\left(\mathrm{n}, \mathrm{n}^{\prime}\right){ }^{93 m} \mathrm{Nb}$ and ${ }^{103} \mathrm{Rh}\left(\mathrm{n}, \mathrm{n}^{\prime}\right){ }^{103 m} \mathrm{Rh},{ }^{n}$ ISSN 0344-8401, Physics Data, Nr 13-2, 1980.

Model calculations are combined with some observed cross sections in these evaluations, and Section 2 of Strohmaier's report indicates that the theoretical values were assinned covariances that take into account that many were obtained using the same parameters. Correlations $=9 \mathrm{gg}$ the model parameters are not considered here; in fact, to do so is difficult because standard compilations of level densities etc. do not contain such information. 


\section{EVALUATION AND REPRESENTATION OF COVARIANCE DATA FOR EVALUATED NUCLEAR CROSS-SECTIONS}

\subsection{Methods, Formats, and Procedures}

In this subsection are included papers on metbodology, papers in which concrete results are given primarily for purposes of illustration. It is intended that this subsection, like the previous sections, include essentially all the available papers.

F. C. Difilippo, SUR, A Program to Generate Error Covariance Files, ORNL/TM-5223, Oak Ridge National Laboratory, March 1976.

This program, based on the paper of F. G. Perey, G. de Saussure, and R. B. Perez below, develops covariance matrices on a preset energy grid. Covariance elements are based on the scatter of the input data sets around the evaluation that is also fed in. A bias in an evaluation, relative to the data used, is not distinguished from scatter. Technically, the covariance data produced are representative of the scatter of the data rather than of their mean. Nonetheless, SUR proved very useful in studying the scatter among many data sets in the production of early covariance matrices published by Drischler (see Section 4 below). A more complete commentary on SUR may be found in Section C 3b of Peelle, 1982, below.

D. M. Hetrick and C. Y. Fu, GLUCS: A Generalized Least-Squares Program for Updating Cross Section Evaluations With Correlated Data Sets, ORNL/TM-7341 (ENDF-303), Oak Ridge National Laboratory, October 1980.

GLUCS accepts prior information on cross sections and uncertainties in ENDF/B format, uses a "Bayes equations" or least-square adjustment approach to include new experimental data with its covariance matrix, and can provide the output updated cross section and covariance data in ENDF/B format. Note that for the assumed sequential evaluation approach to be valid, eacb set of experimental data must be uncorrelated with the data already combined. This program can help solve the routine work of data combination, but of course no such approach is intended to be used in an unthinking mechanical manner. 
W. Mannhart. A Small Guide to Generating Covariances of Experimental Data, Bericht FMRB-84 (ISSN 0341-5666), Physikalisch-Technische Bundesanstalt, Forschungs und Me $\beta$ reaktor Braunschweig, June 1981.

In Section E, this report deals with evaluation in the sense of proper data combination. (See additional notes in Section 1).

R. W. Peelle, "Requirements on Experiment Reporting to Meet Evaluation Needs," pp. 421-429 in Proc. of NEANDC/NEACRP Specialists Meeting on Fast Neutron Fission Cross Sections of U-233, U-235, U-238, and Pu-239, June 28-30, 1976, W. P. Poenitz and A. B. Smith, Editors, ANL-76-90 [ERDANDC-5/L, NEANDC(US)-199/L], Argonne National Laboratory.

This paper presents the use of least-square data combination as a moủel of evaluation technique. Goals were to clarify the merits of the method, indicate the generality beyond the common curve-fitting applications, and state the conditions on the results. One simple example is given. (See additional notes in Section 1).

R. W. Peelle, "Uncertainty in the Nuclear Data for Reactor Calculations," pp. 11-84 in Sensitivity and Uncertainty Analysis of Reactor Performance Paraineters, J. Lewins and M. Becker, Editors, Vol. 14 of Advances in Nuclear Science and Technology, Plenum Press, New York, 1982.

This reference attempts complete coverage of the definition, generation, and representation of covariance information for evaluated nuclear data, but is not uniform in depth. The appropriateness of seeking minimum-variance unbiased solutions is assumed, as is the concept that the routine portion of the work of data combination can be accomplished with the aid of least-square techniques. An attempt is made to clarify the relationship between the standard least-squares and the parameter adjustm n: approaches. Various problems in generation of covariance data are analyzed, including in particula: the propagation of uncertainies in stand - -ds.

F. G. Perey, "Estimated Uncertinties in Nuclear Data -- An Approach," p. 842 in Proc. of Conf. on Nuclear Cross Sections and Technology, R. A. Schrack and C. D. Bowman, Editors, NBS-SP-425, Vol. 2, National Bureau of Standards, 1975.

This paper gives the conceptual underpinning of the ENDF/B covariance files from a somewhat broader point of view than is given in the format manual (cited below!. Additional detail can be found 
in minutes of the Cross Scction Evaluation Working Group (S. Pearlstein, Editor, Brookhaven National Laboratory) for May and December, 1973.

F. G. Perey, The Data Covariance Files for ENDF/B-V, ORNL/TM-5938 (ENDF-249), Oak Ridge National Laboratory, 1978; R. Kinsey, Data Formats and Procedures for the Evaluated Nuclear Data File, ENDF, BNLNCS-50496 (ENDF-102), Brookhaven National Laboratory, 1979.

This report (or the reprint in ENDF-102) gives the procedures and formats for representing covariance data in the ENDF/B-V evaluation. While it does not generally deal with how to obtain the evaluated covariances, one can infer from it some of the classes of required cata. A central determinant of the formats described was the ability for the files to be processed into multigroup files for arbitrary group boundaries.

F. Schmittroth, "A Method for Data Evaluation wi:h Lognormal Distributions," Nucl. Sci. Er.g. 72, i9-34 (i?79).

This paper gives a complete underpinning for a least-squares evaluation system based on the idea of adjustment of a prior evaluation (Bayes' approach). Lognormal density functions are employed to avoid negative results in the presence of large uncertainty and to treat explicitly the approximations that occur if relative uncertainties and parameter adjustments are considered. While some of the choives taken by Schmittroth are not unique, anyone intending to pursue large-scale data combination for evaluation purposes should try to understand if not adopt his points of view. The paper references some of the applicaiions for which this method has already been used.

D. L. Smith, Covariance Matrices and Applications to the Field of Nuclear Data, ANL/NDM-62, Argonne National Laboratory, November 1981.

The author develops the basic principles of evaluation or data combination using least-squares techniques, and exhibits the formulae for various sub-cases. The point is well made that use of such procedures requires extensive scrutiny of input data. (See additional notes in Section 1). 


\subsection{Documented Examples of Nuclear Data Corariance Evaluations}

This subsection includes some of the papers that document nuclear data uncertainty evaluations.

C. Y. Fu and F. G. Perey, Atomic Data and Nuclear Data Tables, 22, 249 (1978).

In this paper the technique of successive inclusion of independent data sets using a least-squares adjustment code is used to obtain values and covariance data for the total cross section of carbon for the region in which scattering from carbon is taken as a standard. To some extent it was necessary to use qualitative considerations to obtain the covariance information for the input experimental data.

C. Y. Fu, D. M. Hetrick, and F. G. Perey, "Simultaneous Evaluation of ${ }^{32} \mathrm{~S}(n, p),{ }^{56} \mathrm{Fe}(n, p),{ }^{65} \mathrm{Cu}(\mathrm{n}, 2 \mathrm{n})$ Cross Sections," p. 63 in Proc. of Conf. on Nuclear Cross Sections For Technology, October 22-26, 1979; J. L. Fowler, C. H. Johnson, and C. D. Bowman, Editors, NBS-SP-594, National Bureau of Standards, September 1980; C. Y. Fu and D. M. Hetrick, "Experience in Using the Covariance of Some ENDF/B-V Dosimetry Cross Sections: Proposed Improvements and Addition of Cross Section Covariances," p. 877 in Proc. of the 4th ASTM-Euratom Sympositum on Reactor Dosimetry, Radiation Metrology Techniques, Data Bases, and Standardizatior, Gaithersburg, MD, March 2, 1982, NUREG/CP-0029.

These papers give positive results of using the least-square adjustment (Bayes' equations) technique for inclusion of new experimental cross section and covariance data with the pre-existing evaluation. Problems encountered included not only data inconsistencies but the ill effects of seemingly overstated input data correlations and of covariance data represented on an energy grid too coarse for this application. These papers illustrate the values that can be obtained by a full treatment of nuclear data uncertainties, but also indicate that special precautions are required if the covariances in an evaluation are to be used to represent prior information for future extensions of that evaluation.

V. A. Kon'shin, E. Sh. Sukhovitskij, and V F. Zharkov, Determination of the Errors in Evaluated Data with Allowance for Correlations, Evaluation of $\sigma_{f}\left({ }^{235} \mathrm{U}\right), \alpha\left({ }^{235} \mathrm{U}\right), \alpha\left({ }^{239} \mathrm{Pu}\right)$ and $\sigma_{f}\left({ }^{239} \mathrm{Pu}\right)$ for the Evaluated Nuclear Data Library BOYaD-3, A. V. Lykov Institute of Heat and Mass Exchange, Academy of Sciences of the Byelorussian SSR, preprint, Minsk, 1978, INDC(CCP)-132/LV, translated by the IAEA, April 1979; independently translated and republished as INDC(CCP)-174/L, January 1982.

Evaluated group criss sections and group covariance matrices are obtained for fission and the ratio of capture to fission based on uncertainties and correlations among the experimental observations. The 
uncertainty components responsible for these correlations are listed. The data are averaged using weights chosen to minimize the variance of the evaluated quantities, taking data correlations into account. Since this is the same goal indicated for the full least squares data combination technique using the inverse covariance matrix as the weight matrix, it would be interesting to know if the techniques are identical in the general case though differently described. The present author did not succeed in answering this question through simple inspection of the formulae displayed for the case with data correlations present.

F. G. Perey, G. de Saussure, and R. B. Perez, "Estimated Data Covariance Files of Evaluated Cross Sections - Examples for ${ }^{235} U$ and ${ }^{238} U, "$ p. 578 in Proc. of Inter. Conf. on Advanced Reaciors: Physics, Design, and Economics, September 8-11, 1974, J. M. Kallfelz and R. A. Karam, Editors, Atlanta, Ga., Pergamon Press, 1975.

The authors derive variance-covariance matrices for an important portion of the neutron energy range based on the scatter among the most-measured experimental cross section data for fast reactors. The technique was extended by Difilippo in SUR (see citation in Section 3.1). While the idea of focusing in this way exclusively on the "external" errors among the world's accumulated data can be attacked, it is impossible to consider the codification of data scatter as irrelevant to the overall data uncertainty problem.

W. A. Reupke and D. W. Muir, "Neutronic Data Consistency Analysis for Lithium Blanket and Shield Design," p. 861 in Proc. of the Second Topical Meeting on the Technology of Controlled Nuclear Fusion, 1976, Vol. 3, Richland, Washington, CONF-760935-P3.

In the section called "Group Cross Section Error Estimates" the authors indicate how the adjustment code ALVIN was used to generate a data covariance matrix entirely on the basis of scatter among the data sets. Only the resulting standard errors are given in this paper. 
E. Sh. Sukhovitskij and V. A. Kon'shin, "Allowance for Correlations in the Determination of the Errors in Evaluated Data," in Translation of Selected Papers Presented at the 4th All-Union Conf. on Neutron Fhysics, Kiev, April 1977, INDC(CCP)-113/U, translated by IAEA.

The authors demonstrate a technique in which the uncertainties in each of the experiments to be combined are subdivided rather completely to permit consideration of which are quite uncorrelated. The technique is illustrated for $\alpha\left({ }^{239} \mathrm{Pu}\right)$. The paper shows real insight in its breakdown of the various categories, but does not make clear how the weights are chosen for the various experiments, although there is reference to "optimized" weights. In particular, there is no comparison to results that would be obtained in a full least square procedure using as a weight matrix the inverse variance-covariance matrix of the input data.

The method of weight optimization is presumably that described by V. A. Kon'shin in the Appendix of INDC(CCP)-94/U, "Review and Evaluation of the ${ }^{235} \mathrm{U}$ Fission Cross Section in the $0.1 \mathrm{keV}-15$ MeV Energy Range," (1976). Additional details are given in Kon'shin et al., cited above.

S. Tagesen, H. Vonach, and B. Strohmaier, "Evaluation of the Cross-Sections for the Reactions ${ }^{24} \mathrm{Mg}(\mathrm{n}, \mathrm{p}){ }^{24} \mathrm{Na},{ }^{64} \mathrm{Zn}(\mathrm{n}, \mathrm{p}){ }^{64} \mathrm{Cu},{ }^{63} \mathrm{Cu}(\mathrm{n}, 2 \mathrm{n}){ }^{62} \mathrm{Cu}$ and ${ }^{90} \mathrm{Zr}(\mathrm{n}, 2 \mathrm{n}){ }^{89} \mathrm{Zr},{ }^{n}$ ISSN 0344-8401, Physics Data, Nr. 13-1, 1979.

A proceciure is described and used for combining data from various experiments. For each energy grid region the data, after examination, are combined using inverse variances as relative weights. The output correlations are determined by using these same relative weights for the correlations for each of the input experiments. The approach is explained as a practical compromise to handle the expected correlations without having to consider the effect of the data correlations on the weighting as in the full least-squares approach using the inverse data variance-covariance matrix to weight the input data.

P. G. Young, Summary Documentation of LASL Nuclear Data Evaluations for ENDF/B-V. (Appendix B), LA-7663-MS, Los Alamns Scientific Laboratory, 1979.

This report contains more complete ENDF/B-V covariance file documentation for ${ }^{1} \mathrm{H},{ }^{6} \mathrm{Li},{ }^{10} \mathrm{~B}$, ${ }^{14} \mathrm{~N},{ }^{16} \mathrm{O}$, and ${ }^{27} \mathrm{Al}$ than can be found in the overall summary document ENDF-201. It appears that 
both quantitative and semiquantitative techniques were employed based on estimated uncertainties in the data and the scatter among data sets. At least for ${ }^{6} \mathrm{Li}$ and ${ }^{10} \mathrm{~B}$, the covariance matrix given by the least-squares R-matrix analysis was employed. 


\section{COMPILATIONS OF CROSS SECTION COVARIANCE DATA}

The most complete compilation of covariance data availesle is that contained in the ENDF/B-V covariance files and briefly documented in ENDF-201, BNL-NCS-17541, 3rd edition (ENDF/B-V), compiled by R. Kinsey (1979). This section contains references to some processed multigroup covariance matrix library reports and to the paper by Perey giving qualitative documentation for the ENDF/B-V covariance files based on his review of most of the information included.

J. D. Drischler and C. R. Weisbin, Compilation of Multigroup Cross-Section Covariance Matrices for Several Important Reactor Materials, ORNL-5318, Oak Ridge National Laboratory, 1977.

Processed multigroup covariance libraries obtained using the PUFF module of the MINX code are illustrated and tabulated. The coverage includes important reactions in up to 10 nuclides common in fast-spectrum systems. Weighting spectra are representative of Godiva, an LMFBR core (ZPR-6/7), and LMFBR shields (1/E). The results are processed in up to 15 energy groups. These files are based on the ENDF/B-IV covariance data supplemented by partial evaluations that were locally available at ORNL and documented in appendices to the report.

Muct of the covariance information on which this report is based became outdated with the release of ENDF/B-Y. The report is therefore of interest primarily for comparison purposes to indicate how corcriance data have changed with inclusion of new data and with use of different evaluation techniques.

D. W. Muir and R. J. LaBauve, COFILS, A 30-Group Covariance Library Based on ENDF/B-V, LA8733-MS (ENDF-306), Los Alamos Scientific Laboratory, March 1981.

The 30-group COVFILS multigroup cross section and covariance library, based on ENDF/B-V, is described and illustrated. The weighting functions used in the processing are not explicitly given in this report, but are stated to be taken from practical fusion-system neutronics applications. The retrieval code is listed that makes values available and produces useful gray-shaded graphic displays of correlation matrices. (See Section 7 for additional notes.) 
F. G. Perey, "Expectations for ENDF/B-V Covariance Files: Coverage, Strength, and Limitations," p. 311 in Proc. of a Seminar-Workshop on $A$ Review of the Theory and Application of Sensitivity and Uncertainty Analysis, Oak Ridge, Tenn., ORNL/RSIC-42, Radiation Shielding Information Center, Oak Ridge National Laboratory, February 1979.

This paper explores the concepts underlying the covariance data in ENDF/B-V. Uncertainties are distinguished from mistakes, for example. The coverage by material and reaction type is given, and the strengths and weaknesses of the resulting file are qualitatively assessed. The overall conclusion of the report is: "We do not expect at this stage that the quality of the (V-5) files will be such that strong conclusions can be based upon them" (emphasis added). This conclusion was disappointing to those who spent much effort preparing for use of the files and saw immediate strong need, but it still rings true among most of the uncertainty evaluators. However, this conclusion does not mean that no conclusions can be drawn using the covariance files, and by contrast even more limited conclusions on projected uncertainties would have been possible if the ENDF/B-V uncertainty files did not exist.

J. D. Smith and B. L. Broadhead, Multigroup Covariance Matrices for Fast Reactor Studies, ORNL/TM-7389, Oak Ridge National Laboratory, 1981.

For twelve materials, this report illustrates the 52-group covariance matrices derived from ENDF/B-V covariance files using the PUFF-II code. The same results are tabulated after being collapsed to 13 energy groups. An all-purpose weighting function was employed that might cause difficulty for specific applications because, for example, the uncertainty ascribed to the thermal cross section for fission of ${ }^{235} \mathrm{U}$ is thereby applied up to an energy of $450 \mathrm{eV}$.

The Coverx output format of PUFF II is described. 


\section{THE UNCERTAINTIES IN NUCLEAR SYSTEM ANALYSIS RESULTS THAT ARE INDUCED BY NUCLEAR DATA UNCERTAINTIES}

This section cites reports in which first-order uncertainty propagation is employed to assess the uncertainty in calculated results. Some of the papers are also concerned with biases or uncertainties related to the analysis methods. The listing is far from complete, and the comments are confined to unusual features. Note that analyses of this type are intrinsic to efforts at cross section adjustment, so many of the papers in Section 6 contain material that would be appropriate here.

J. Butler, "Nuclear Data for Reactor Shielding," p. 28 in Proc. of Inter. Conf. on Neutron Physics and Nuclear Data for Reactors and Other Applied Purposes, Atomic Energy Establishment, Harwell, United Kingciom, September 1978.

In Section 5 of this paper, Butler propagates early cross section uncertainty estimates to obtain uncertainties for shield performance for thermal and fast reactors and for a $14-\mathrm{MeV}$ source. If the uncertainties used are reasonable, the paper illustrates that the small-error approximation may not ajways be valid for shielding problems because large sensitivity coefficients occur. (Second-order sensitivity analyses are not now routinely available).

S. A. W. Gerstl, R. J. LaBauve, and P. G. Young, A Comprehensive Neutron Cross-Section and Secondary Energy Distribution Uncertainty Analysis for a Fusion Reactor, LA-8333-MS, Los Alamos Scientific Laboratory, 1980.

This report describes and gives results from a shield performance uncertainty analysis for a documented fusion power reactor design. The reported responses include one heating rate and two materials damage endpoints. This analysis includes the effect of uncertainty in secondary energy distributions using the "hot-cold" two-group separation of the secondary neutron spectrum. The corresponding uncertainties in the secondary energy distribution are not available in ENDF/B-V. At least for copper, these uncertainties were estimated to be of important magnitude.

D. J. Dudziak, "Cross Section Sensitivity and Uncertainty Analysis for Fusion Reactors," in Nuclear Data for Fusion Reactor Technology. IAEA-TECDOC-223, International Atomic Energy Agency, 1979.

This paper is a general review of cross section uncertainty analysis for fusion system designs. 
S. A. W. Gerstl, D. J. Dudziak, and D. W. Muir, "Cross-Section Sensitivity and Uncertainty Analysis with Application to a Fusion Reactor," Nucl. Sci. Eng. 62, 137-156 (1977); LA-6118-MS, Los Alamos Scientific Laboratory, 1975, for an earlier detailed report of the same work.

This paper presents a thorough and understandable development of uncertainty analysis with particular attention to performance parameters of the Tokomak Fusion Test Reactor. Based on available uncertainty estimates, activation rate and biological dose uncertainties are assessed.

S. A. W. Gerstl, "Uncertainty Analyses for Secondary Energy Distributions," p. 219 in A Review of the Theory and Application of Sensitivity and Uncertainty Analysis Proceedings of a Seminar-Workshop. August 22-24, 1978, C. R. Weisbin et al., Editors, ORNL/RSIC-42, Radiation Shielding Information Center, Oak Ridge National Laboratory.

This paper details how the uncertainty in the shape of a neutron secondary energy distribution can be propagated to its effect on a computed quantity. In particular, the "hot-cold" spectrum shape parameterization is explained.

E. I. Inyutin and E. A. Khodarev, "Progress Report on Fast Reactors in the USSR as of March 1981," 14th Annual Conference of the International Working Group on Fast Reactors, International Atomic Energy Agency, March 31, 1981. (Translated from Russian oy Language Services, Knoxville, Tenn., OLS-81-61).

This paper, on page 18 of the translation, refers to a covariance matrix for the BNAB-78 and BNAB-MIKRO neutron data systems. The neutron cross section covariance data set is stated to cover ten important reactor fuel, coolant, and structure materials. Projected uncertainties in fast reactor core performance parameters are quoted to be smaller than had been estimated previously (in the USSR).

C. R. Weisbin et al., Cross Section and Method Uncertainties: The Application of Sensitivity Analysis to Study Their Relationship in Radiation Transport Benchmark Problems, ORNL/TM-4847 (ENDF218), Oak Kidge National Laboratory, August 1975.

Uncertainties in methods and nuclear data are considered relative to an air transport benchmark problem. Section VI contains the details of the treatment of nuclear data uncertainty. Appendix B is a guide to the PUFF uncertainty file processing code of MINX. Appendix C illustrates the data files used for nitrogen and oxygen. 
D. W. Muir, "Data Covariance Estimation Methods for Sensitivity-Based Data Assessment," Trans. Am. Nucl. Soc. 26, 484 (1977).

Use of nuclear cross section uncertainty data to determine the most important nuclear data deficiencies is discussed. Use of supplemental uncertainty information is prescribed if ENDF/B-V does not contain the required information.

M. Salvatores, "Neutron Transport in Structural Materials and Shielding Design," p. 275 in Proc. Conf on Nuclear Cross Sections and Technology, Octoier 22-24, 1979, Knoxville, Tenn., J. L. Fowler, C. H. Johnson, and C. D. Bowman, Editors, NBS-SP-594, National Bureau of Standards, 1980.

Available covariance matrices were used to obtain the cross-section-related uncertainties in some computed results for sodium and iron-sodium shields (p. 279). 


\section{COMBINATION OF DIFFERENTIAL AND INTEGRAL DATA UTILIZING COMPLETE COVARIANCE DATA}

The literature of cross section "adjustment" and related efforts is a rich one, so the selection of titles below may not reflect the full diversity available. All these papers implicitly contain also the idea of propagation of evaluated nuclear data uncertainties, using first-order theory, to obtain the uncertainties in (and the correlations among) the results computed from these data.

J. B. Dragt et al., "Methods of Adjustment and Error Evaluation of Neutron Capture Cross Sections; Application to Fission Product Nuclides," Nucl. Sci. Eng. 62, 119 (1977).

This paper, together with reports referenced therein, covers a complete program of determination and adjustment of fission product capture cross sections. Altogether, the work described in this paper has been quite influential. (See additional notes in Section 2.)

A. Gandini, Nuclear Data and Integral Measurements Correlations for Fast Reactors, Part I: Statistical Formulation, CNEN-RT/FI(73)5, and Part II: Review of Methods, CNEN-RT/FI(73)22, Comitato Nazionale Energia Nucleare, 1973.

These early papers have been quite influential in the development of nuclear data adjustment techniques. While the formalism included full covariance information, such data were not available.

D. R. Harris, W. A. Reupke, and W. B. Wilson, Consistency Among Differential Nuclear Data and Integral Observations: The ALVIN Code for Data Adjustment, for Sensitivity Calculations, and for Identification of Inconsisient Data, LA-5987, Las Alamos Scientific Laboratory, December 1975.

This paper documents the theory and use of a computer program for combination of differential nuclear data with the results of integral experiments. Complete variance-covariance information is assumed for both classes of input data. Particular attention is paid to the internal consistency of the combined data set and to techniques that may be employed to focus on data elements that are the source of inconsistency. Code details are given. 
J. L. Lucius and J. H. Marable, "Influence of Fission Spectra Uncertainties on Calculated Fast Reactor Parameters," Trans. Am. Nucl. Soc. 32, 731 (June 1979).

Fission neutron spectrum uncertainties are parameterized here in terms of uncertainties in two rather orthogonal quantities, the spectrum mean and variance. The sensitivities of ZPR-5/7 results to changes in these quantities are determined to permit display of the propagated uncertainties in the results computed using ENDF/B-IV. Inclusion of data from several benchmark integrai experiments indicated adjustments to fission neutron spectra from ENDF/B-IV in a direction consistent with changes already proposed for version $V$.

J. H. Marable, C. R. Weisbin, and G. de Saussure, "Uncertainty in the Breeding Ratio of a Large LMFBR: Theory and Results," Nuct. Sci. Eng. 75, 30-55 (1980); J. H. Marable, "Combination of Differential and Integral Data," Sensitivity and Uncertainty Analysis of Reactor Performance Parameters, Vol. 14 of Advances In Nuclear Science and Technology, J. Lewins and M. Becker, Editors, Plenum Press, New York, 1982.

These references attempt a complete treatment of the combination of integral and differential data leading to "adjusted" multigroup cross section sets in the context of fast reactor analysis. Certain data elements are omitted for lack of developed technique, for example, self-shieiding factors. Methods uncertainties are treated through use of "calculational bias factors."

J. H. Marable and C. R. Weisbin, "Advances in Fast Reactor Sensitivity and Uncertainty Allalysis," p. 25 in $A$ Review of the Theory and Application of Sensitivity and Uncertainty Analysis. Proc. of a Seminar-Workshop, ORNL/RSIC-42, Radiation Shielding Information Center, Oak Ridge National Laboratory, 1979.

The 1978 status of uncertainty analysis is reviewed as it applies to fast reactors. A geometric approach is taken to elucidate the solution of the least-squares data adjustment problem. Methods uncertainties are treated. The uncertainty in a result computed using adjusted data is expanded taking into account terms that are not usually written such as the uncertainties in the input covariance data. The author of the present bibliography is unsure what status these extra terms should have for the analysis of small adjustments, since they appear to him to be second-order terms and all second-order terms are not included. In any case, it can be instructive to consider the form of these terms. 
S. Pearlstein, "interrelating Differential and Integral Nuclear Data," Nucl. Sci. Eng. 74, 215 (1980).

The author comments on the process of data adjustment and illustrates his points with a simple example. The conclusion is that adjusted data should best "...be regarded as a parameterization of the integral data validated only when (the adjusted data are) acting in specific combinations." The note is a useful counterpoise to provoke thought about the values and limitations of adjusted data sets.

F. G. Perey, Contributions to Few-Channel Spectrum Unfolding, ORNL/TM-6267, Oak Ridge National Laboratory, 1978. This report reprints the the follcwing separate papers: F. G. Perey, Uncertainty Analysis of Dosimetry Spectrum Unfolding, second EURATOM Symposium on Reactor Dosimetry, Palo Alto, Calif., October 3, 1977; F. G. Perey, Spectrum Unfolding by the Least Squares Method, IAEA Technical Committee on Current Status of Neutron Spectrum Unfolding, Oak Ridge, Tenn., October 12, 1977.

This report gives theory and commentary on the solution of the few-channel spectrum unfolding problem. Here, this common reactor dosimetry problem is treated as an adjustment problem in which prior knowledge of spectrum (and cross sections) is updated using new experimental reaction rate information. Full covariance information is contemplated for all quantities involved. The described techniques have proven to be useful. The present author questions only the stated imperative against any iterative form of solution including any in which the required sensitivity coefficients (i.e. derivatives of :stimated activiations to cross section or flux components) are recalculated at refined rather than prior values of the variables.

W. A. Reupke and D. W. Muir, "Neutronic Data Consistency Analysis for Lithium Blanket and Shield Design," p. 861 in Proc. of the Second Topical Meeting on the Technology of Controlled Nuclear Fusion, 1976, Vol. 3, Richland, Washington, CONF-760935-P3; W. A. Reupke, The Consistency of Differential and Integral Thermonuclear Neutronics Data, LA-7067-T, Los Alamos Scientific Laboratory, 1978.

The ${ }^{7} \mathrm{Li}\left(n, n^{\prime} \alpha\right) T$ cross section is adjusted based on estimated uncertainties in cross section data and in the integral tritium production benchmarks. (See additional notes in Section 3.2 above). 
F. Schmittroth and R. E. Schenter, "Finite Element Basis in Data Adjustment," Nucl. Sci. Eng. 74, 168 (1980).

This paper formalizes the adjustment problem for data parameterized by a piecewise linear approximation. This basis is often convenient, as seen in the ENDF/B representations, so it is helpful to have an analysis of the implications of its use for cross section data combination problems.

E. T. Tomlinson, G. de Saussure, and C. R. Weisbin, Sensitivity Analysis of TRX-2 Lattice Paramerers With emphasis on Epithermal ${ }^{238} U$ Capture, EPRI-IN-346 (ENDF-252), prepared at Oak Ridge National Laboratory for Electric Power Research Institute, March 1977.

An uncertainty analysis was performed for an important benchmark experiment critical lattice for thermal reactors. Calculated estimates of the observed quantities were consistent with experiment taking into account the available uncertainty files, and an adjustment was performed. Appendix B is the documentation for the ${ }^{235} U(n, f)$ and $(n, \gamma)$ uncertainty files still in use for ENDF/B-V.

A. A. Van'kov, A. I. Voropaev, and L. N. Yurova, Analysis of Reactor Physics Experiments, Atomizdat, Moscow, 1977, NP-tr-1988, as translated by D. Hough, Risley draft translation 3193, 1977.

This reference is a rather complete monograph on the development of fast-reactor whysics data analysis. Uncertainties in differential and integral experiments and in calculational methods are considered and the text reflects much thought on the ways all the information may be combined to solve fastreactor design problems. The introduction contains an unusually comprehensive review of the development of ideas in this area, and indeed the strongest value of this book is the key it gives to the literature familiar to its authors. Specific fast-reactor data problems are addressed. In data combination and experiment planning, this monograph gives more emphasis than most sources to the formal information content of particular experiments.

C. R. Weisbin et al., "Application of Sersitivity and Uncertainty Methodology to Fast Reactor Integral Experiment Analysis," Nucl. Sci. Eng. 66, 307-333 (1978).

A comprehensive uncertainty analysis was performed for three fast-spectrum benchmark critical experiments. Analyses were performed with and without inclusion of the critical experiment results to 
adjust the micioscopic group cross sections. Fission spectrum, inelastic scattering spectrum, and selfshieiding factor uncertainties were not included. Sensitivities for "reset" criticality were defined but not employed.

C. R. Weisbin and R. W. Peelle, "Propagation of Uncertainties in Fission Cross Section Standards in the Interpretation and Utilization of Critical Benchmark Measurements, ${ }^{n}$ pp. 269-277 in Proc. Inter. Specialists Symp. on Netstron Standards and Applications, NBS-493, National Bureau Standards, October 1977.

Using early ORNL covariance files, the impacts were examined of uncertainties in the standard ${ }^{235} \mathrm{U}(\mathrm{n}, \mathrm{f})$ cross section on analyses of the clean metal Godiva $\left({ }^{235} \mathrm{U}\right)$ and Jezebel $\left({ }^{239} \mathrm{Pu}\right)$ fast-spectrum critical experiments. Conclusions were highly tentative because inelastic scattering uncertainties were not included. The impact of the ${ }^{235} \mathrm{U}(\mathrm{n}, \mathrm{f})$ standard cross section uncertainties appeared important even for the plutonium assembly.

D. W. Wootan and F. Schmittroth, Comparison of SAND-II and FERRET, HEDL-TC-1589, Hanford Engineering Development Laboratory, January 1981.

For the dosimetry spectrum unfolding problem, FERRET uses a least-square adjusiment method with full representation of input uncertainty information for all quantities, while SAND-II uses an iterative solution technique that has been traditional in this field. The interesting comparison of results includes useful documentation of FERRET solutions for the illustrative examples. 


\section{DESCRIPTIONS OF COMPUTER CODES THAT PRODUCE OR MANIPULATE NUCLEA $R$ DATA COVARIANCE FILES}

From the examination of the earlier sections it is apparent that many computer codes process variance-covariance matrices for input or output; the names of many of these programs are given above. In this section are included some reports that primarily document computer codes rather than the underlying analysis techniques or their applications.

J. D. Drischler, J. H. Marable, and C. R. Weisbin, COVERT and CAVALIER: Two Computer Codes for Estimating Uncertainties of Calculated Neutronics Parameters Using Standard Interface Files SENPRO and COVERX, ORNL/TM-6078 (ENDF-256), Oak Ridge National Laboratory, August 1978.

COVERT and CAVALIER are documented. The former converts binary covariance files (COVERX format) to card images (and reverse) for data interchange, while the latter combines covariance matrices in COVERX format with sensitivity coefficients in SENPRO format to obtain uncertainties in the corresponding computed results.

R. E. MacFarlene, D. W. Muir, and R. M. Boicourt, The NJOY Nuclear Data Processing System, Vol. It: User's Manual, LA-9303-M, Los Alamos Scientific Laboratory, 1982.

The ERRORR module of the NJOY system producEs processed multigroup variance-covariance matrices. If provided with a resonance-reconstructed point cross section set, ERRORR can also produce the necessary multigroup cross sections. The COVR module of NJOY reads the multigroup data output by ERRORR and produces standard plots of relative standard deviation and gray-shaded graphic representations of the correlation matrices. At least for some cases, this representation is quite lucid. However, COVR does require the availability of the DISSPLA proprietary plotting software package. The NJOY document includes code description, operating instructions, etc., for both the ERRORR and COVR modules. 
D. W. Muir and R. J. LaBauve, COVFILS, A 30-Group Covariance Library Based on ENDF/B-V, LA-8733-MS (ENDF-306), Los Alamos Scientific Laboratory, 1981.

The retrieval code for the COVFILS multigroup covariance library is listed, and the covariance processing vapability of the NJOY program is implied. (See additional notes in Section 4 above.)

F. G. Perey, Least-Squares Dosimeter Unfolding: The Program STAYSL, ORNL/TM-6062 (ENDF-254), Oak Ridge National Laboratory, 1977.

This report documents an adjustment-type, least-squares program useful for neutron dosimetry based on reaction rate measures. (See F. G. Perey, ORNL/TM-6267, in Section 6 above for the related theory).

F. Schmittroth and D. W. Wootan, Covariances for Dosimeter Cross Sections, TC-1588, Hanford Engineering Development Laboratory, December 1979.

Section 3 of this report describes a smail code useful for putting some covariance data in a format suitable for FERRET input. The representations for covariance data in this report have proved useful to Schmittroth and his coworkers, but seem somewhat arbitrary to the present author because the pattern of the off-diagonal covariance terms is not obtained solely from the underlying experiments. However, when providers of data do not include covariance data, users must make approximations.

J. D. Smith, III and B. L. Broadhead, Multigroup Covariance Matrices for Fast Reactor Studies, ORNL/TM-7389 (ENDF-305), Oak Ridge National Laboratory, 1981.

The retrieval code for covariance material stored in COVERX format is given. The capabilities of the PUFF-II stand-alone covariance processing code are described and input requirements are given. (See additional notes in Section 4 above).

J. D. Smith III, Processing ENDF/B-V Uncertainty Data Into Multigroup Covariance Matrices, ORNL/TM-7221 (ENDF-295), Oak Ridge National Laboratory, June 1980.

This report documents PUFF-II, a stand-alone multigroup covariance matrix processing code for uncertainty data in ENDF/B format. 


\section{ACKNOWLED'MMNTS}

The authors are indebted to Douglas Muir and to Herbert Vonach for calling attention to a number of works for inclusion in this bibliography. We also thank Sol Pearlstein of the NNDC at Brookhaven National Laboratory for his persistent interest in this project and its potential value to evaluators and users of nuclear data. Stephanie Raby is acknowledged for clarifying the citations and preparing the typescript. 